more specialized method based upon it. However, the price for selectivity is overgeneralization, the risk of misleading the reader. By and large the authors have avoided this problem.

I am less happy about the lack of theory, particularly in the final chapters on in situ hybridization, autoradiography and the measurement of chromosomal DNA. I accept that the authors have provided extensive references to more technical papers. But one aim for a book of this type is that it should be reasonably selfcontained. I would also like to have seen a fuller discussion of the pitfalls in the interpretation of data. To give but one example, a method is given for the in situ hybridization of DNA probes to chromosomal RNA. This technique is valuable, especially for transcripts from non-repetitive sequences (not considered by Macgregor and Varley) but must be well controlled against the artefact of DNADNA hybridization. The methods for controlling this technique are, unhappily, not included.

There will, however, be few cytologists who cannot read this book for profit. Macgregor and Varley have written a useful introduction to modern methods for working with animal chromosomes, and have done so in a most readable way.

Michael Ashburner is Reader in Developmental Genetics at the University of Cambridge.

\section{Language of physics}

\section{Nevill Mott}

\section{Reflexions d'un Physicien.}

By Anatole Abragam.

Hermann, 293 rue Lecourbe, 75015

Paris: 1983. Pp.152. FF 58.

ANATOLE Abragam is one of the most distinguished of French theoretical physicists; he is now a professor at the Collège de France, and was this year elected as a foreign member of the Royal Society. His speciality has been research on nuclear magnetism. The atomic nucleus carries a small magnetic moment, which can be detected by resonance methods, and nuclear magnetic resonance (NMR) is now a useful tool in many branches of science.

This book contains lectures, articles and letters from throughout Abragam's career. A third of it is taken up with two lectures on nuclear magnetism, the first of which, given in 1960 at the Collège de France, tells amusingly how research on NMR started independently in Stanford and in Harvard, with different concepts and techniques. For years afterwards one could tell from which side of the continent a researcher came "plus surement que par son accent". The second continues the story from 1960 to the present day, giving a very readable account of the present position of his subject. "Magnus" he calls it, rejecting "Magnuc", a current abbreviation, because of its ugliness.

Abragam is sensitive to the way things are written. He claims that George Orwell was right about one thing - the corruption of language. So I turned with interest to his article on the use of the French language in scientific communication. Abragam is a realist; he appreciates the position of English - "broken English" - and knows that nearly everyone will use it to make themselves widely understood. But while the Anglophones will suffer by seeing their language debased, the young French scientists, forced to learn a foreign language, will the better appreciate and use their own. Scientific French must however be preserved, and Abragam calls for a government subsidy to enable major books by French scientists to be published in French and English.

On big science and little science, in an article written in 1968, there is much good sense; we must have big science, he says, but must be careful not to lose our souls to it; " propter vitam, vitae perdere causas". And in an appendix written 15 years later for this volume, he wonders if big science and little science are terms that have lost their validity in this age of microelectronics. He quotes with dismay the view of one of the most brilliant of American theorists, that the key to the unsolved problems of today lies in the computer. He hopes that in physics this is not so - and compares his feelings with those of the wife of Bishop Wilberforce, who hearing the doctrine that man is descended from the apes, said "if this horrible rumour turns out to be true, let us pray to God that it does not get widely known".

There is much else - a moving tribute to his friend and teacher John van Vleck; a letter on Orlov; and "La Physique, pour quoi Faire?", an address to the French Physical Society in 1973, which gives a passionate defence of our science. This last is perhaps a period piece; the call for relevance, the anti-intellectualism of popular culture, may have been stronger at that time than now. Physics stands for truth, he says, and the disorientation of youth is a result of the lies that pervade our society. He does not evade the question of scientists and defence. Yes, he says, to the scientists who worked on radar in the years before 1939 , no, to those who were developing weapons for the Vietnam war. On the whole, he feels that scientists can have a good conscience if they do good science.

Professor Abragam has a lot to say; he says it with wit and clarity; and his French is a joy to read.

Sir Nevill Mott was Cavendish Professor of Physics at the University of Cambridge from 1953 until his retirement in 1971. He was editor of the series International Monographs on Physics, published by Oxford University Press, in which Professor Abragam's Principles of Nuclear Magnetism appeared in 1961.

\section{Insects organized}

Ingrid H. Williams

Social Insects: Ecology

and Behavioural Biology.

By M. V. Brian.

Chapman and Hall: 1983. Pp.377.

Hbk $£ 25, \$ 49.95$; pbk $£ 12.95, \$ 25$.

THERE are few scientists with the breadth of knowledge and understanding of social insect biology who could attempt a comparative treatment of all eusocial insects. M. V. Brian is one of these few. In Social Insects he has succeeded in collating a vast amount of scattered research literature, most of it published during the last ten years, into a comprehensive treatise which will undoubtedly become a standard work of reference.

Evolutionary trends and comparative ethology are the underlying themes of the book. There are seventeen chapters, each of which is further subdivided to enable the reader to find particular topics without difficulty. Dr Brian starts with food collection and description of diverse foraging strategies of increasing complexity, moving on to give examples of social insect nest structure and construction, and an account of the means by which suitable microclimates are selected and maintained. A further chapter is devoted to the different weapons and social organizations evolved for effective colony defence.

Efficient food collection must be followed by efficient food processing, and here the importance of evolutionary trends to increase food preparation by adults for their young and to greater differentiation of a nursing caste to increase food conversion efficiency are stressed. This leads naturally to chapters on population growth, colony maturation and reproduction, with evaluation of the relative merits of the theories of kin selection, material manipulation and polygyne family selection in explaining the success of the evolution of sociality in Hymenoptera. Dr Brian next deals with maintenance of colony integrity, and compares the roles of queens in monogyne and polygyne colonies, before rounding off the book with a discussion of speciation and examples of the cooperative and competitive interrelationships involved in species coexistence at the community level.

The text is augmented by useful figures and some excellent photographs; the reference list is extensive and the subject and author indexes comprehensive. Written with the expert in mind, because it assumes a basic knowledge of social insects, non-specialists will also find the book fascinating and informative.

Ingrid $H$. Williams is a Senior Scientific Officer in the Department of Entomology, Rothamsted Experimental Station, Hertfordshire. 